J. Dairy Sci. 95:1022-1022

doi:10.3168/jds.2012-95-2-1022

(C) American Dairy Science Association ${ }^{\circledR}, 2012$.

\title{
Erratum to "Short communication: Effects of $\beta$-lactoglobulin, stearoyl-coenzyme A desaturase 1, and sterol regulatory element binding protein gene allelic variants on milk production, composition, acidity, and coagulation properties of Brown Swiss cows” (J. Dairy Sci. 95:450-454)
}

\author{
A. Cecchinato, C. Ribeca, A. Maurmayr, M. Penasa, M. De Marchi, N. P. P. Macciotta, M. Mele, P. Secchiari, \\ G. Pagnacco, and G. Bittante
}

The following paragraph was omitted from page 451: Calculations of allele frequencies and tests of HardyWeinberg equilibrium were carried out using Genepop software (Raymond and Rousset, 1995). An association study for the $L G B, S C D$, and $S R E B P-1$ gene variants was performed using Bayesian methodology. Milk production, quality, and MCP were analyzed from 294 records. The model included effects of DIM class (6 levels), parity (first, second, third, and greater than third), and the effect of $L G B, S C D$, and SREBP-1 genotypes (with 3 levels each: CC, CT, TT for $L G B$; CC, CT, TT for $S C D$; and LL, LS, SS for SREBP-1). The model also included the effects of additive sire $(\mathbf{u})$, herd $(\mathbf{h})$, and residual (e). Note that test-day effects were confounded with herd effects, because all cows in a given herd were sampled on the same day, with sampling days differing among herds. Prior distributions for the additive genetic effects in $\mathbf{u}$ and herd effects in $\mathbf{h}$ were normal densities: $p\left(\mathbf{u} \mid \sigma_{u}^{2}\right) \sim N\left(0, \mathbf{A} \sigma_{u}^{2}\right), p\left(h \mid \sigma_{h}^{2}\right) \sim N\left(0, \mathbf{I} \sigma_{h}^{2}\right)$, where $\mathbf{A}$ was the numerator relationship matrix among sires, I was the identity matrix, and $\sigma_{u}^{2}$ and $\sigma_{h}^{2}$ were additive genetic and herd variances, respectively. Flat priors were used for systematic effects and dispersion parameters. Marginal posterior distributions of all parameters were obtained using the Gibbs sampler (Gelfand and Smith, 1990). In the present work, the Gibbs sampler ran with a single chain of 100,000 points, and the first 10,000 were discarded as burn-in, previously tested by the Raftery and Lewis (1992) methodology. Our Bayesian approach considered the marginal posterior distribution of half of the difference between the estimated effects of homozygous genotypes (i.e., the additive effect). The posterior median was used as point estimate of parameters of concern. Lower and upper bounds of the $95 \%$ highest posterior probability density regions for additive and dominance effects were estimated from the Gibbs samples. In this case, the posterior probability $(\boldsymbol{P})$ was the probability of a difference being greater than zero for positive effects or lower than zero for negative effects; from here, we considered an effect as relevant when the posterior probability over (or below) zero was $>0.90$.

Upon discovery of the error, corrected files (PDF and full-text versions) were posted to the journal online, but the print version could not be corrected before the time of printing. The journal regrets the error.

\section{REFERENCES}

Cecchinato, A., C. Ribeca, A. Maurmayr, M. Penasa, M. De Marchi, N. P. P. Macciotta, M. Mele, P. Secchiari, G. Pagnacco, and G. Bittante. 2012. Short communication: Effects of $\beta$-lactoglobulin, stearoyl-coenzyme A desaturase 1, and sterol regulatory element binding protein gene allelic variants on milk production, composition, acidity, and coagulation properties of Brown Swiss cows. J Dairy Sci. 95(1):450-454. 